\title{
Behavioral addictions-a social science perspective
}

\author{
Karin Helmersson Bergmark* \\ Department of Sociology and Addiction Research Group, Stockholm University S-10691 Stockholm, Sweden
}

\begin{abstract}
This conceptual review and analysis discusses the development of the addiction concept, a development that entails a marked expansion of what is considered to constitute an addiction. During the last decade, following the introduction of DSM-5 (the Diagnostic and Statistical Manual of Mental Disorders, APA 2013) [1] and the opening up of new terrains, many bad habits and behavioral problems are in the process of being transferred to and renamed as addictions, endorsing a continued or rather reinforced medicalization of social problems. In this paper a social science viewpoint is suggested as a more appropriate perspective on these matters.
\end{abstract}

\section{Behavioral addiction or behavioral problem?}

This paper presents a discussion on the debated concept of behavioral addiction. Building on, or rather copied from, indicators of substance use problems in such diagnostic manuals as DSM, the development and use of the concept has mainly taken place within a medical science context. In this paper I suggest a social science model, i.e., a return to such ideas as habituation, aiming at an alternative interpretation of behavioral addiction and the problems related to the concept.

For a long time, addiction was conceptually confined to excessive use of alcohol and substances such as opioids, and motivated by the substance itself as well as by consequences of such use. In recent decades, however, we have seen an accelerating expansion of the sphere for which addiction is seen as an appropriate conceptual framework. Some relate this to the consumer society of our times [2], and the construction of disordered identities within expanding premises of consumption, such as gamblers, bulimics and Internet addicts [3].

Many of these 'new' addictions are related to life online. These perceived problems-"behavioral addictions"-refer to online gambling as well as, for example, gaming or networking. Public health authorities in Europe have not yet addressed behavioral addictions as a public health concern, other than for gambling, but private clinics have proliferated to meet the market for advice and treatment [4]. In China, for example, boot camps work to "wean off" excessive online habits among teenagers [5]. Importantly, these clinics run interventions directed at presumed "internet addicts", despite the fact that there is little in-depth knowledge about the actual nature of the problems, how they manifest among different individuals and groups, and how they might be "cured".

\section{The concept of addiction}

The meanings associated with the addiction concept are varied, and though there is indeed a common interpretation, every understanding has its unique features, reflecting the era and the surrounding society. Up until the late 1900s, the concept of addiction was only used related to the excessive use of alcohol and other habit-forming substances. Subsequently, addiction $v$ s. dependence are fairly 'modern' concepts in that before the 1900s scholars discussed the roots of repeated drunkenness not in terms of disease, but more as a consequence of inherent weakness of will. There were some exceptions, such as Thomas Trotter, who in 1804 described the habit of drunkenness as a disease, and Magnus Huss, whose publication, Alcoholismus chronicus (Chronic Alcohol Disease), came out in 1851. The intention, for Trotter and Huss as well as for later disease proponents, was to dismantle the moral condemnation of the drunkard and to reduce the trailing stigma in order to facilitate a change of habits. Later on, Harry Levine (1978) claimed that "addiction" as well as the related idea of "loss of control" were conceptually constructed in western society as a consequence of an emerging modernity entailing the increasing significance of selfcontrol.

Inebriety and drunkenness continued to be the prime concepts also in the 1930s, when the Alcoholics Anonymous (AA) 12 steps program was formulated. The AA disease model was not presented as scholarly; AA was and is a laymen's mutual help fellowship [6] aiming at sobriety via a suggested program and an explanatory model using metaphors and the sharing of examples-their life stories. Inspired by the AA program and work, E.M. Jellinek later on published The Disease Concept of Alcoholism (1960), wherein a disease model claiming scientific support was presented. In Jellinek's model, loss of control, craving, withdrawal, and tolerance were key concepts, and in tandem with the growing success of this disease model, the World health Organization (WHO) advocated a conceptual change from addiction and habituation to dependence in order to cover a broader set of substances, such as cannabis, nicotine and cocaine (WHO, 1964).

Until fairly recently, thus, dependence has been the concept used in the two major classifications of psychiatric disorders: the International Classification of Diseases (ICD), in which dependence was first included in the ninth version from $1977,{ }^{1}$ and the Diagnostic and ${ }^{1}$ https://www.cdc.gov/nchs/icd/icd9.htm

${ }^{\star}$ Correspondence to: Karin Helmersson Bergmark, Department of Sociology and Adiction Research Group, Stockholm University S-10691 Stockholm, Sweden, Tel: +46 08-16 20 71; E-mail: karin.bergmark@sociology.su.se

Key words: Behavioral addiction, social problem, conceptual development, review, medicalization, habituation

Received: May 02, 2018; Accepted: May 14, 2018; Published: May 17, 2018 
Statistical Manual of Mental Disorders (DSM), where dependence was first introduced in 1987, but where changes in the new DSM-5 (APA, 2013) to include the category of addiction entailed a return from exile of the addiction concept. DSM-5 constituted an important shift in that "substance-related and addictive abuse and dependency" was relabeled "substance-related and addictive disorders", which comprise not only substance-based addictions, but also gambling, i.e., a "behavioral addiction". In addition to gambling, Internet Gaming Disorder was placed in an appendix with a call for more research aiming at future inclusion in the manual. Another step in the same direction was taken in a disputed ICD proposal for the $201811^{\text {th }}$ edition of introducing a new "gaming disorder" category $[7,8]$.

One reason behind the shift in DSM-5 was the risk of confusion over different definitions of dependence [9], as physical dependence may well develop in connection with prescribed medications such as beta-blockers, entailing tolerance and withdrawal but no harmful consequences. The shift in DSM-5 can be interpreted as a change from a focus on physical dependence to a focus on harmful consequences as a core part of the addiction concept.

The proponents of expanding the addiction concept to comprise behavioral addictions are based in several and partly opposing theoretical traditions. Claims vary from psychological perspectives underlining that any type of activity that is perceived as pleasurable can develop into an addiction $[10,11]$, to neurophysiology, where addiction is related to the brain's reward system [12]. The growing importance and relative dominance of a neurobiological perspective on addiction (Keane, op.cit.) is in itself part of a more general medicalization process, incorporating also a change in 'common knowledge' or the layman perspective on these issues. In fact in Wikipedia, ${ }^{2}$ under the heading "addiction", we find it described as "... a brain disorder characterized by compulsive engagement in rewarding stimuli .... The term behavioral addiction correctly refers to a compulsion to

engage in a natural reward," a rather bold statement giving the impression of a conceptual consensus regarding both physical and behavioural addictions.

Chamberlain et al. [13] claim that "Structurally, internet gaming addiction has been linked with reduced grey matter density in inferior frontal gyrus, cingulate, insula, precuneus, and hippocampus; along with lower white matter density in related regions". (2016, p.847). But what does this mean? The problems related to claiming addiction to be a brain disease and a good object for neuroscience research is elucidated in a recent piece in The Lancet [14], of which one plausible interpretation is that the fairly large group of authors display evident difficulties in reaching any conclusions that all could agree on. Similarities between behavioral and substance addiction are claimed to be proven with "growing evidence", but from studies comprising 10-17 subjects (and corresponding numbers in control groups). The power of these studies is not impressive and even if it was, there are still no tenable explanations of, e.g., MRI findings. A circumstance that supports restrictive interpretations [15] of the meaningfulness of conceptualizing addiction as a neurobiological disease is the fact that even though the theory has achieved considerable scientific prominence, its clinical influence has so far been limited, and it is still far from fulfilling the promises originally articulated by its proponents. In fact, after 20 years of very expensive research there is still little evidence of progress and no tenable explanations of mechanisms involved [16].

${ }^{2}$ https://www.wikipedia.org/

\section{Behavioral addiction, a Trojan horse?}

Today, excessive involvement in any type of consumption or activity can be considered an addiction, i.e., a psychiatric disorder [17]. Research in this field has grown exceedingly; the number of behavioural addiction papers was tenfold in 2014 compared with 1990 (Ibid.), and similarly, the number of Internet Addiction papers grew even more steeply between 2000 and 2013 [18].

There are good reasons to believe that the notion of behavioral addictions will play an increasingly important role in terms of the number of people that will be considered to be suffering from them, as diagnosed by professionals as well as identified by their own designation. Against the background of such a scenario it is of utmost importance to know whether and how behavioral addictions deviate from other types of addictions, along with their unique manifestations and prognosis over time, but much research on Internet and behavioral addictions has been based on skewed or convenience samples (Ibid.); in the case of Internet addiction, for example, the research has been biased towards high frequency users of the Internet.

The emergence of the concept of behavioral addiction as well as of Internet addiction coincides with a more general process of medicalization, whereby a variety of social problems are being defined as medical-as illness, disorder, or pathology, along with processes of promoting the establishment and evaluation of interventions into evidence-based practices. In this connection it has been suggested that the evidence-based-practice movement is itself a "medicalization engine" [19], establishing a medical conceptualization through its emphasis on standardized assessment and diagnosis. In my view, however, the discussion and research on behavioral addictions is still mainly indiscriminating when it comes to how the concept is defined, measured and judged.

Block [20] suggests that for Internet addiction, tolerance could be measured by a need for better equipment (computers) as well as by extended time online. But, as Billieux, et al. (op.cit) argue, no one would dream of judging a devoted guitar player as displaying tolerance when the musician demands a better guitar or more training hours. Yet, they continue with stating that we "cruelly lack a theoretically sound model" for behavioral addictions.

The Billieux group (Ibid.) unite around two mandatory concepts defining a pathological condition: functional impairment and stability, i.e., persistence. A fundamental component of most perspectives on the addiction phenomenon is that addiction is persistent, i.e., characterized by the fact that it has a strong tendency not to spontaneously go away. However, the fact is that many of the rare studies that have utilized a longitudinal design have come up with results that undermine the merging of the substance use and the behavioral addictions problems. In fact, different behavioral addictions display few proofs of persistence [21]. Instead, it seems as if spontaneous recovery and volatility are what characterize this sphere of experienced problems. When help-seeking questions are included in a longitudinal study covering exercise, sex, shopping, online chat, video gaming and eating (Ibid.), only a minority (and for most problems, frequencies "too low to conduct comparisons", p.9) of respondents confirming experiences of behavioral addictions report on having sought help for the problem. In his recent work on addiction and choice, Heather [22] suggests that the very core of addiction is to be found in "the struggle to change a way of behaving that, implicitly, one knows to be harmful but cannot easily shake off" (p.12). ${ }^{3}$ Two U.S. national surveys were used in another study analyzing

${ }^{3}$ Hence excluding those who Skog (2003) labeled as "consonant" addicts; i.e. who would have problems quitting the habit if trying. 
lifetime and past-year DSM-lV-diagnoses of and treatment-seeking for pathological gambling [23]; also in this study, proofs of persistence are scarce. Only a minority of respondents reported excessive gambling episodes lasting more than one year, and few (7-12\%) had sought help from healthcare or 12 step groups. Similarly, in a study of Canadian gamblers [24] only a small fraction (6\%) of those with lifetime gambling problems at any level had ever used treatment services, including selfhelp materials. The SWELOG study, a longitudinal study of problematic gambling in Sweden, has produced results that are in line with this; in an eleven-year follow-up of problem gamblers, $24 \%$ were considered as at-risk gamblers, $7 \%$ as problem gamblers and only $6 \%$ as "probable pathological gamblers" (Public Health Agency of Sweden, 2015). Only $2 \%$ of persons denoted as problem gamblers at year one had, during the eleven years, sought help for their gambling (Ibid.).

In a panel study by Van Rooij [25] covering just one year, only half of the respondents classified as Internet addicted in year 1 could be identified as such in year ${ }^{2}$. This finding implies that extensive online gaming may be characterized as transitory rather than as persistent. In 2002, Salguero and colleagues published an early attempt to define and demarcate addiction to computer games. They concluded that, when given the type of adapted instruments for measurement of substance disorders that nowadays is the standard tool also for behavioral addictions, data pointed at good consistency. Hence, a number of problems related to excessive gaming were identified and the authors conclude that gaming for some is a behavior resembling "dependence". On the other hand, they add that for competitive play, responses might reflect competition rather than pathology and they also raise the need for proofs of persistence. Yet, as proofs of persistence are rare to find, results (Ibid.) should not be interpreted as support for the addiction track. There are some exceptions; Gentile, et al. [26] found in a study of "pathological video game use" (2011) that $84 \%$ of boys initially labeled as "pathological gamers" remained in this category two years later. This group also displayed more psychiatric symptoms (depression, anxiety, social phobias) than others.

Hormes and colleagues [27] conclude, drawing on a cross-sectional survey with U.S. undergraduate students, that use of social networking sites is potentially addictive. Craving for Facebook was common in this study and almost $10 \%$ of respondents met the criteria used for disordered online social networking use. As in other studies, modified tests from the alcohol/substance field were used and significant relations were found between networking addiction, Internet addiction and problem drinking. Also, psychological problems were reported on significantly more often in the addicted group, indicating the option of interpreting the excessive networking as coping, i.e., a secondary problem.

The fact that measures of behavioral addiction are retrieved or "translated" from the efforts to measure problem drinking/substance use is rarely problematized or questioned. Some seem not to make any distinction at all between Internet use/addiction and substance use/ addiction, in using wordings such as "other types of substance use" for behavioral addictions [28]. When some researchers state that "the diagnostic criteria for pathological gambling is similar to substance dependence..." [29], the reader needs to be reminded that there are no objective observations underpinning the logic for such similarities, but that the basis is the use of the same questionnaires, only adapted to the specific addiction at hand for study [30].

Starcevic [31], who focuses on repetitive and problematic behavior and poor impulse control, warns against simplification of the addiction concept and foresees that unless further explored more thoroughly we will see an "...uncontrolled expansion of the catalogue of behavioural addictions, drastic lowering of the diagnostic threshold and spurious epidemics of all sorts..." (p.724). He points to disparities between traditional addictions and behavioral addictions when it comes to the interpretation of excessive use, preoccupation, tolerance and abstinence, while Sellman suggests a solution to this problem by launching the idea of the concept "behavioural health disorders" (2016 p. 806), claiming that this would solve these problems. Griffiths [32], on the other hand, assumes tolerance and withdrawal symptoms to be mandatory for the labeling of anything as addiction.

Keane (op.cit.) argues that it would be relevant to redefine addiction from being the problem of a stigmatized minority to something that affects the majority; not originating from problem areas but instead from activities "not only morally neutral but positively valued and encouraged" (p.373). Adding to the confusion, Wei et al. [33] describe in a commentary that $91.8 \%$ of teenagers in Singapore seeking treatment for excessive computer gaming were gaming daily, hence the $8.2 \%$ of the teenagers that obviously played computer games less often than daily yet were treated for gaming problems. A significant proportion of the treatment seekers had previous conduct disorder (32\%) and mental health diagnoses $(42 \%)$, indicating that there were other problems in the teenagers' lives leading up to excessive gaming.

One thing is certain: behavioral addictions carry with them infinite possibilities of establishing additional addictions, but they also carry with them a limitation of "marking" special substances as more dangerous than other things, so that the concept of addiction is in movement to another "explanatory field" where the substance no longer is the focal point. This Trojan horse can easily be transformed into a Pandora's box, which opened once, cannot be closed again; new addictions will continue to pop up. And this question remains: what will the consequences be of letting behavioral addictions into the realm of medical issues?

\section{Concepts matter! Revitalising a social science perspective on addiction}

The lack of sound theoretical underpinnings for the inclusion of behavioral addictions into the catalog of psychiatric diagnoses has been pointed out also by other researchers [34,35], who emphasize the option of considering the signs of behavioral addiction as coping strategies explained by an underlying disorder, such as depression or problems of impulse control [36]. Too, there is certainly no consensus on the expanded addiction concept. Warnings have come from within the DSM-lV task force [37,38], but also other agents [39] have attacked DSM-5 for its medicalization of life in general as well as the suggested inclusion of behavioral addictions, arguing that this inclusion may blur the addiction concept to the point where it potentially includes everything in life that we enjoy doing. Even from other perspectives, critical voices have been heard. ${ }^{4}$

Instead of seriously and intently investigating the concept of behavioral addiction and its implications, most studies in this field are confirmative rather than explorative [40]. Lack of theoretical specificity for the new disorders in parallel with a reliance on using criteria for already existing disorders to identify new disorders, does imply that the measurements used to explore new behavioral addictions cannot account for the potentially unique aspects of the problem behaviors.

For example, as King and Delfabbro [42] write, it is unclear whether preoccupation with video games is problematic in the same way as

${ }^{4}$ Also psychiatrists have reacted against the subjectivity of DSM/ICD classifications and called for a new nosology based on neuroscience [41]. 
preoccupation with gambling, since the outcome and progress of video gaming is determined much more by a player's choices and inputs to the game. Such unique aspects are neglected when traditional addiction criteria are used to define the boundaries of the problem behavior. Therefore, even though behavioral addictions are being paid increased attention in research, there is a persistent lack of knowledge about how these addictions might be expressed if identification of the problem behavior was not constrained by traditional addiction criteria based in a biomedical tradition [43].

Furthermore, although a number of researchers [44-46] might be correct in their claims that behavioral addictions share certain features with substance addictions, it is obvious that there is also a distinct difference between a substance addiction and a behavioral addiction, the former identified as an addiction primarily due to specific characteristics of a limited set of substances, presumed to be capable of enslaving those who consume them due to inherent dependence generating qualities of the substance. Still, in a review of Internet addiction studies $[18,47]$ we saw that on the one hand the number of studies has increased exponentially in the new millennium, while on the other hand, there was a lack of longitudinal studies in this field as well as a domination of confirmatory studies at the expense of critical discussions of discourses and concepts.

The question of whether one may have a behavioral addiction can at present not be given an explicit answer that everyone would agree on. Basically, any attempt to answer the question is dependent on how addiction is defined. As a consequence of the lack of consensus, I find it hard to identify any diagnostic system or theoretical framework that can be seen as fully satisfactory in terms of providing a definition that also contains an explanatory mechanism for the causal processes.

However, this positioning does not imply that we do not recognize the presence of problems in relation to the phenomena that are designated as behavioral addictions, but at the same time there is also a clear tendency to 'over-medicalization' in the professional as well as in the lay discourse. In a previous study [48], we analyzed available research on addiction claims of frequent use of MMORP games. Results pointed at substantial problems in connection with attempts to establish consistent conceptual frameworks underpinning an addiction diagnosis for individuals with frequent use and problems associated with that use. It is, similarly, important to understand that such a conclusion does not exclude the presence of problems that can be related to, e.g., frequent gaming; problems do indeed occur for individuals due to their gaming activities, but it remains doubtful whether or not such problems should be the basis for an addiction diagnosis. ${ }^{5}$

A useful way forward would be to try to understand the particular concerns that have developed in society around problem behaviors, how these problems typically manifest and whether they are persistent. If certain activities have a tendency to lead to more problems, or exacerbate existing problems, why is that the case? For example, Sussman, et al. [49)] argue that availability is the most important factor in developing addictive behavior. This circumstance is well in line with the general perspective on the main determinants for classic addictions such as to alcohol and to drugs [50]. However, it is as yet unknown whether Internet availability impacts on the risk of developing a behavioral addiction to certain online activities, or challenges of distinguishing a healthy fascination from harmful behavior and brain disease in a society where the Internet is ubiquitous.

${ }^{5}$ https://www.internetworldstats.com/stats4.htm
A fruitful approach to studying potential problem behaviors with such challenging conceptualization might be to abandon the idea of addiction as a specific delimited phenomenon. Rather, we might normalize it by pointing to the fact that habits of the heart, activities central to one's way of life, may be hard to change even if the activity brings on problems [51]. Such a perspective can be seen as congruent with a long list of activities that are currently called addictions. Along the same line of normalization is the approach developed by the Alcohol Research Group in Berkeley during the 1960s for alcohol problems: "Our use of the term problem drinker here instead of the term alcoholic is not accidental. We wish to avoid getting into the question, 'what is a real alcoholic', or 'does the person have the disease called alcoholism?' We take the point of view that any problem - connected fairly closely with drinking - constitutes a problem." [52]. Such a perspective would be useful also for Internet-related problem behaviors, as it is unlikely that researchers will reach a consensus on whether such behavioral addictions constitute 'real'

addictions or not; this is largely a semantic question depending on the definition of addiction. Thus, we might work within a framework of behavioral addictions by considering the problems that occur as consequences of persistent and excessive Internet use, but without treating it as a specific delimited phenomenon in the manner of a mental disorder.

It is unclear how the biomedical discourse of addiction shapes our contemporary understanding of Internet addiction and other proposed behavioral addictions, which is important, as it impacts on how society perceives and treats people who spend a lot of time online. There is also the wider question regarding the extent to which the identification of behavioral addictions is related to a more pervasive change and widening of the medicalization processes that researchers have identified [53-55]. These questions are relevant not only in order to understand the potential risks of increased Internet use in society, but also to heed Allen Frances' (op.cit.) warning that the changes to the DSM might result in over-diagnosing of unproblematic behaviors.

\section{Acknowledgements}

This work was supported by Vetenskapsrådet (the Swedish Research Council) under Grant 2016-02239 and Riksbankens Jubileumsfond (the Swedish Foundation for Humanities and Social Sciences) under Grant (FSK 15-08961).

A previous version was presented at the 43rd Annual Alcohol Epidemiology Symposium of the Kettil Bruun Society. Thanks go to Eleanor Rapier for language editing.

\section{Conflicts of Interest}

There is no conflict of interest.

\section{References}

1. APA (2013) American Psychiatric Association. (5th Edn) Diagnostic and statistical manual of mental disorders Washington, DC.

2. Keane H (2017) Addiction: Critical Reflections on a Debated Concept. The SAGE Handbook of Drug and Alcohol Studies. Los Angeles.

3. Reith $\mathrm{G}$ (2004) Consumption and its discontents: addiction, identity and the problems of freedom. Br J Sociol 55: 283-300. [Crossref]

4. King D, Delfabbro P, Griffiths M (2010) Cognitive behavioural therapy for problematic video game players: Conceptual considerations and practice issues. J Cyber Ther Rehabil.

5. King DL, Delfabbro PH, Griffiths MD, Gradisar M (2011) Assessing clinical trials of Internet addiction treatment: A systematic review and CONSORT evaluation. Clin Psychol Rev 31: 1110-1116. 
6. Mäkelä K, Arminen I, Bloomfield K, Eisenbach-Stangl I, Helmersson Bergmark K, et al. (1996). Alcoholics Anonymous as a mutual-help movement: A study in eight societies. Univ of Wisconsin Press.

7. Aarseth E, Bean AM, Boonen H, Colder CM, Coulson M, et al. (2017) Scholars' open debate paper on the World Health Organization ICD-11 Gaming Disorder proposal. $J$ Behav Addict 3: 267.

8. Van Rooij A, Ferguson C, Carras M, Kardefelt-Winther D, Shi J, et al. (2018) A weak scientific basis for gaming disorder: Let us err on the side of caution. $J$ Behav Addict 7: $1-9$.

9. O'Brien C (2011) Addiction and dependence in DSM-V. Addiction 106: 866-867.

10. Orford J (2001) Addiction as excessive appetite. Addiction 96: 121-130

11. Peele $S$ (1985) The meaning of Addiction: compulsive experience and its interpretation. Lexington: Lexington Books.

12. Potenza M (2006) Should addictive disorders include non-substance-related disorders? Addiction 101: 142-151.

13. Chamberlain SR, Lochner C, Stein DJ, Goudriaan AE, van Holst RJ, et al. (2016). Behavioural addiction-A rising tide? Eur Neuropsychopharmacol 26: 841-855

14. Yücel M, Carter A, Allen AR, Balleine B, Clark L, et al. (2017) Personal View: Neuroscience in gambling policy and treatment: an interdisciplinary perspective. The Lancet Psychiatry 4501-4506.

15. Kalant H (2010) What neurobiology cannot tell us about addiction. Addiction 105: 780789. [Crossref]

16. Midanik L (2012) Conversation with Lorraine Midanik. Addiction 107: 1906-1914. [Crossref]

17. Billieux J, Schimmenti A, Khazaal Y, Maurage P, Heeren A (2015) Are we overpathologizing everyday life? A tenable blueprint for behavioral addiction research. J Behav Addict 4: 119-123.

18. Bergmark KH, Stensson, E, Bergmark A (2016) Internet addiction-the making of an addiction. Forthcoming in Jacobs $J$ addict and ther.

19. Bergmark A (2014) Medikalisering som evidensbasering-om nedmonteringen av ett social perspektiv på missbruksproblem. In: Petterson U (Ed) Tre decennier med socialtjänstlagen. Gleerup: Malmö.

20. Block JJ (2008) Issues for DSM-V: internet addiction. Am J Psychiatry 165: 306-307. [Crossref]

21. Konkolÿ Thege B, Woodin EM, Hodgins DC, Williams RJ (2015) Natural course of behavioral addictions: a 5-year longitudinal study. BMC psychiatry 15: 4.

22. Heather N (2016) On defining addiction. In: Heather, N. \& Segal, G. eds. 2016 Addiction and Choice: Rethinking the Relationship ( $1^{\text {st }}$ Edn) Oxford, UK.

23. Slutske WS (2006) Natural recovery and treatment-seeking in pathological gambling: Results of two US national surveys. Am J Psychiatry 163: 297-302.

24. Suurvali H, Hodgins D, Toneatto T, Cunningham J (2008) Treatment seeking among Ontario problem gamblers: Results of a population survey. Psychiatr Serv 59: 13431346.

25. Van Rooij AJ, Schoenmakers TM, Van de Eijnden RJ, Van de Mheen D (2010) Compulsive internet use: the role of online gaming and other internet applications. $J$ Adolesc Health 47: 51-57.

26. Gentile DA, Choo H, Liau A, Sim T, Li D, et al. (2011) Pathological video game use among youths: a two-year longitudinal study. Pediatrics 127: 319-329. [Crossref]

27. Hormes JM, Kearns B, Timko CA (2014) Craving Facebook? Behavioral addiction to online social networking and its association with emotion regulation deficits. Addiction 109: 2079-2088

28. Baggio S, Iglesias K, Berchtold A, Suris JC (2016) Measuring internet use: comparisons of different assessments and with internet addiction. Addict Res Theory 12: 1-7.

29. Johansson A, Götestam KG (2004). Problems with computer games without monetary reward: similarity to pathological gambling. Psychol Rep 95: 641-650.

30. Beard KW, Wolf EM (2001) Modification in the proposed diagnostic criteria for Internet addiction. Cyberpsychol Behav 4: 377-383.

31. Starcevic V (2016) Behavioural addictions: A challenge for psychopathology and psychiatric nosology. Aust N Z J Psychiatry 50: 721-725.

32. Griffiths M (2005) A 'components' model of addiction within a biopsychosocia framework. J Subst Use 10: 191-197.
33. Wei MWC, Le HK, Gomez B, Koh PK, Guo S (2016) Profile of adolescents seeking treatment for excessive computer gaming at an addiction treatment service in Singapore. Aust N Z J Psychiatry.

34. Aarseth E, Bean AM, Boonen H, Colder CM, Coulson M, et al. (2017) Scholars' open debate paper on the World Health Organization ICD-11 Gaming Disorder proposal. J Behav Addict 3: 267.

35. Van Rooij A, Ferguson C, Carras M, Kardefelt-Winther D, Shi J, et al. (2018) A weak scientific basis for gaming disorder: Let us err on the side of caution. $J$ Behav Addict 7: $1-9$

36. Kardefelt-Winther D, Heeren A, Schimmenti A, van Rooij A, Maurage P, et al. (2017) How can we conceptualize behavioural addiction without pathologizing common behaviours? Addiction 112: 1709-1715.

37. Frances A (2010) DSM-5 suggests opening the door to behavioral addictions.

38. Frances AJ, Widiger T (2012) Psychiatric diagnosis: lessons from the DSM-IV past and cautions for the DSM-5 future. Annu Rev Clin Psychol 8: 109-130. [Crossref]

39. Pickersgill MD (2014) Debating DSM-5: diagnosis and the sociology of critique. J Med Ethics 40: 521-525.

40. Bergmark KH, Stensson, E, Bergmark A (2016) Internet addiction-the making of an addiction. Forthcoming in Jacobs $J$ addict and ther.

41. Schildkrout B (2016) How to Move Beyond the Diagnostic and Statistical Manual of Mental Disorders/International Classification of Diseases. J Nerv Ment Dis 204: 723 727.

42. King DL, Delfabbro PH (2014) The cognitive psychology of Internet gaming disorder Clin Psychol Rev 34: 298-308.

43. Kardefelt-Winther D (2015) Excessive internet use-fascination or compulsion? [PhD Thesis]. London: London School of Economics and Political Science.

44. Griffiths MD (1996) Behavioural addiction: an issue for everybody? Employee Counselling Today.

45. Marks I (1990) Behavioural (non-chemical) addictions. Br J Addict 85: 1389-1394. [Crossref]

46. Petry N (2006) Should the scope of addictive behaviors be broadened to include pathological gambling? Addiction 101: 152-160.

47. Stensson E (2015) Internet Addiction Studies: A Multiple Correspondence Analysis (MCA) of Research Articles Between 2000 and 2013. Dept of Sociology, Stockholm University.

48. Bergmark KH, Bergmark A (2009). The diffusion of addiction to the field of MMORPGs. Nordic Studies on Alcohol and Drugs 26: 415-426.

49. Sussman S, Leventhal A, Bluthenthal RN, Freimuth M, Forster M, et al. (2011) A framework for the specificity of addictions. Int J Environ Res Public Health 8: 3399 3415. [Crossref]

50. Babor T, Caetano R, Casswell S (2010) Alcohol: No Ordinary Commodity: Research and Public Policy. Oxford, Oxford University Press.

51. Fingarette H (1988) Heavy drinking: the myth of alcoholism as a disease. Berkeley: University of California Press.

52. Knupfer G (1967) The Epidemiology of Problem Drinking. Am J Public Health 57: 973-986.

53. Clarke A, Shim J, Mamo L, Fosket J, Fishman (2003) Biomedicalization: Technoscientific Transformations of Health, Illness and the U.S. Am Sociol Rev 68 161-194.

54. Conrad P, Schneider JW (1992) Deviance and Medicalization: From Badness to Sickness. Philadelphia.

55. Conrad P, Waggoner M (2012) Medicalization. Blackwell Encyclopedia of Health and Society, Blackwell, London.

Copyright: (C2018 Bergmark KH. This is an open-access article distributed under the terms of the Creative Commons Attribution License, which permits unrestricted use, distribution, and reproduction in any medium, provided the original author and source are credited. 